\title{
Survey
}

\section{Innate immune activation of NFKB and its antagonism by poxviruses}

\author{
Gareth Brady, Andrew G. Bowie* \\ School of Biochemistry and Immunology, Trinity Biomedical Sciences Institute, Trinity College Dublin, Dublin 2, Ireland
}

\section{A R T I C L E IN I F O}

\section{Article history:}

Available online $\mathrm{xxx}$

\section{Keywords:}

Viral immune evasion

Poxvirus

$\mathrm{NFKB}$

IL-1

TNF

\begin{abstract}
A B S T R A C T
In recent years there has been an acceleration of discovery in the field of innate anti-viral immunity to the point that many of the key events in early virus sensing and the discrete anti-viral responses they trigger have been elucidated in detail. In particular, pattern recognition receptors (PRRs) that detect viruses at the plasma membrane, in endosomes, and within the cytosol have been characterized. Upon stimulation by viruses, most of these PRRs trigger signal transduction pathways culminating in NFKB activation. NFKB contributes both to type I interferon induction, and to production of pro-inflammatory cytokines from infected cells. Our understanding of host anti-viral innate immunity has been greatly aided by an appreciation of the ways in which poxviruses have evolved strategies to inhibit both innate sensing and effector responses. A recurring feature of poxviral immunomodulation is the apparent necessity for poxviruses to evolve multiple, non-redundant inhibitors of NFKB activation which often appear to act on the same innate signalling pathway. The reason for such apparent over-targeting of one transcription factor is not clear. Here we describe the current understanding of how host cells sense poxvirus infection to trigger signalling pathways leading to NFKB activation and pro-inflammatory cytokine induction, and the ways in which poxviruses have evolved to concisely antagonize these systems.
\end{abstract}

() 2014 Published by Elsevier Ltd.

\section{Contents}

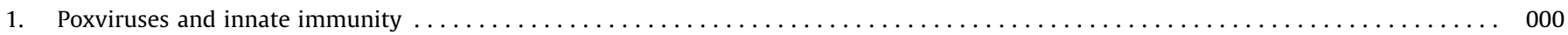

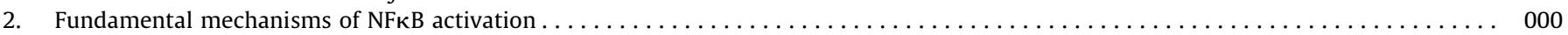

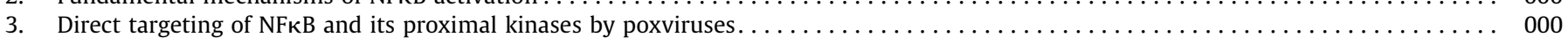

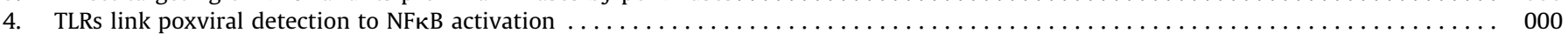

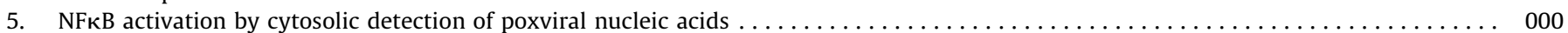

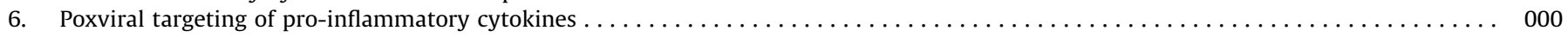

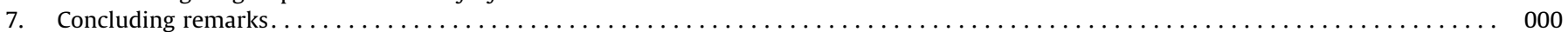

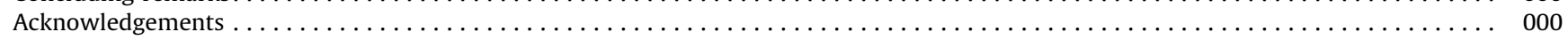

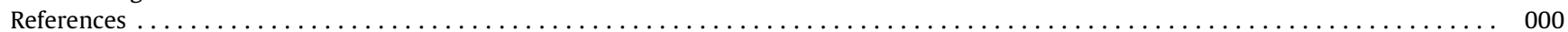

Abbreviations: NFкB, nuclear factor КB; MCV, Molluscum contagiosum virus; PPV, parapox virus; MYXV, myxoma virus; CMPV, camelpox virus; VARV, variola virus; VACV, vaccinia virus; MPV, monkeypox virus; ECTV, ectromelia virus; CPV, cowpox virus; PRR, pattern recognition receptor; PAMP, pathogen associated molecular pattern; DAMP, damage associated molecular pattern; TI-IFN, type I interferon; IL-1, interleukin-1; TNF, tumor necrosis factor; IRF, IFN regulatory factor; RHD, Rel Homology Domain; IKK, IкB kinase; NEMO, NFKB essential modulator; $\beta$-TrCP, $\beta$-transducin repeat-containing protein; MSK1, mitogen and stress-activated kinase-1; Vflip, FLICE-like protein; dsRNA, double stranded RNA; TIR, Toll-IL-1R; TRIF, TIR-domain-containing adapter-inducing interferon- $\beta$; RIP1, receptor-interacting protein 1; TRAF, TNF receptorassociated factor; TAK1, transforming growth factor beta-activated kinase 1; TLR, toll-like receptor; RSV, respiratory syncytial virus; VSV, vesicular stomatitis virus; cDC, conventional dendritic cell; pDC, plasmacytoid dendritic cell; FLDC, Flt3 ligand-mobilized DC; MyD88, myeloid differentiation primary response gene 88; Mal, MyD88adapter-like; TRAM, TRIF-related adapter molecule; VIPER, viral inhibitory peptide of TLR4; IRAK2, interleukin-1 receptor-associated kinase 2; MVA, modified vaccinia Ankara; RLRs, RIG-I-like receptors; MDA5, melanoma differentiation factor 5; RIG-I, retinoic acid-inducible gene; MAVS, mitochondrial antiviral signalling; STING, stimulator of IFN genes; TBK1, tank binding kinase 1; Cgamp, cyclic-GMP-AMP; cGAS, cGAMP synthase; DNA-PK, DNA-dependent protein kinase; CARD9, caspase-associated recruitment domain 9; AIM2, absent in melanoma 2; ASC, apoptotic speck protein..

* Corresponding author. Tel.: +3531 8962435; fax: +35316772400.

E-mail addresses: bradyg1@tcd.ie (G. Brady), agbowie@tcd.ie (A.G. Bowie). 


\section{Poxviruses and innate immunity}

Under the constant selective pressure of pathogens, immunity is the most rapidly evolving system in vertebrates. All viruses evolve strategies to inhibit or evade host immunity leading to minimally symptomatic and persistent infection once virus-host adaptation is optimally attuned. Poxviruses are particularly adept at targeting innate immunity in a precise and efficient manner. Poxviral immune evasion genes collectively form a toolbox of inhibitors and decoys targeting the rate-limiting steps in host anti-viral signalling pathways. Consequently, poxviruses have long served as unparalleled tutors of molecular immunity by pinpointing the genes and processes that hosts have evolved to combat them.

Poxviruses are large, enveloped, double-stranded DNA viruses, which exclusively replicate in the cytoplasm of infected cells. To date, the genomes of all sequenced poxviruses are between 134 and $365 \mathrm{~kb}$ and contain between 130 and 328 predicted open reading frames (ORFs) [1,2]. Poxviruses are grouped into two subfamilies: the Chordopoxvirinae, which infect vertebrates, and the Entomopoxvirinae, which infect invertebrates. Chordopoxvirinae are subdivided into ten distinct genera: orthopoxviruses, yatapoxviruses, leporipoxviruses, capripoxviruses, cervidpoxviruses, suipoxviruses, parapoxviruses, molluscipoxviruses, crocodylipoxviruses and avipoxviruses (Table 1). Chordopoxviruses can be also grouped into four phylogenetic categories in order of divergence [3]. Group I is the most divergent and includes the Avipoxvirus genera with Fowlpox (FPV) and Canarypox viruses. Group II, the second most divergent, includes Molluscipoxvirus with Molluscum contagiosum virus (MCV) and Parapoxvirus (PPV) genera. The remaining two groups III and IV are clustered together and are often referred as to as 'sister groups' based on the relative proximity of their grouping on the phylogenetic tree. Group III comprises members of Capripoxvirus, Leporipoxvirus such as myxoma virus (MYXV), Suipoxvirus and Yatapoxvirus genera and Group IV includes the seven members of the Orthopoxvirus genera such as camelpoxvirus (CMPV), variola virus (VARV), vaccinia virus (VACV), monkeypox virus (MPV), ectromelia virus (ECTV) and cowpox virus (CPV).

Chordopoxviruses exhibit striking variation in the range of host species that can be productively infected by a given virus. This 'host range' can be experimentally correlated with the presence of defined 'host range genes' which are commonly immunomodulators that block divergent host specific anti-viral responses [4]. These genes are under strong evolutionary selection and vary dramatically even between similar species within a genus [5]. For example, whilst the now extinct causative agent of smallpox,

Table 1

Representative viruses from the ten Chordopoxvirus genera.

\begin{tabular}{ll}
\hline Genus & Species \\
\hline Avipoxvirus & Canarypox virus (CPV) \\
& Fowlpox virus (FPV) \\
Capripoxvirus & Sheepox virus (SPV) \\
Cervidpoxvirus & Deerpox virus (DPV) \\
Crocodylipoxvirus & Crocodilepox virus \\
Leporipoxvirus & Myxoma virus (MYXV) \\
Molluscipoxvirus & Molluscum contagiosum virus (MCV) \\
Orthopoxvirus & Vaccinia virus (VACV) \\
& Variola virus (VARV) \\
& Camelpox virus (CMPV) \\
& Coxpox virus (CPV) \\
& Ectromelia virus (ECTV) \\
Parapoxvirus & Monkeypoxvirus (MPV) \\
Suipoxvirus & Orf virus \\
Yatapoxvirus & Swinepox virus ${ }^{\mathrm{a}}$ \\
\hline
\end{tabular}

${ }^{a}$ Not discussed in this review
VARV, was strictly human-infectious, the closely related CPV and MPV naturally infect a wide variety of mammalian species. Despite this, most poxviruses can at least enter a wide variety of cells from many different animal species in a fashion that is mostly independent of species-specific receptors, but rather involves virion proteins that are conserved in all poxviruses [6]. However some poxviruses are incapable of replicating in hosts or even cells to which they are not strictly adapted, such as MCV which only appears to efficiently infect human keratinocytes [7].

Approximately 50 relatively conserved genes are found in all sequenced poxviruses and another 40 genes are common to most chordopoxviruses [8]. These genes are chiefly located in the central region of the genomes and exhibit the least divergence between poxvirus family members. Unsurprisingly, such conserved genes control the essential activities of poxvirus biology such as transcription, RNA processing, replication and virion assembly. Conversely, genes that are involved in host-virus interactions generally map towards the terminal regions of the genome. These exhibit lower sequence identity to their orthologs in other poxviruses, with a more diverse distribution between lineages. Most are dispensable for virus replication in cell culture models yet their targeted deletion almost invariably results in viral attenuation in infection models where a complex in vivo environment and multi-cellular anti-viral immunity confront virus propagation and survival. As such, the majority of these 'non-essential' genes facilitate immune evasion and operate at a number of levels in inhibiting virus detection machinery, their signalling networks and downstream effector systems. It has long been known that poxviruses readily recombine with non-viral sequences in vivo [9] and viral immunomodulators thus likely originate from recombination events with host genetic information, as well as through mutation and evolution of pre-existing viral genes to new functionalities with high rates of diversifying evolution [10]. A recent study shed a fascinating new light on how poxvirus evolution functions by acquiring flexible genomic 'accordions' of tandem duplications after which copies undergo genetic drift and deletion once advantageous new variants are derived [11]. Identification of immune-regulatory sequences in some cases occurs when the viral genome has been sequenced and sequence homology to known host immune genes is observed. Functional characterization of putative immunomodulators thus proceeds along lines predicated on how well the host system is understood at the time of investigation. However, most sequences bear no obvious similarity to host sequences and require screening for immune-regulatory potential based on suspected viral activity during infection. Most poxviral immunoregulators are expressed immediately after entry to inhibit the early stages of anti-viral immunity before an effective response to the virus can be mounted.

There has been an acceleration in discoveries in the field of antiviral innate immunity in the past decade which has led to an increasing awareness of the multitude of viral immunoregulators that exist to target innate immunity. Moreover, the wave of discovery of host innate immune mechanisms for pathogen detection has in no small part been aided by studying the ways in which poxviruses target these systems. The mechanism of early viral sensing in cells hinges on distinguishing host from viral products by germline-encoded pattern recognition receptors (PRRs) which survey extracellular and intracellular contents for pattern associated molecular patterns (PAMPs) or damage associated molecular patterns (DAMPs) produced as a consequence of viral infection [12]. These drive the innate anti-viral response which ultimately accelerates the acquisition of adaptive immunity leading to effective virus clearance and long term immunity. Sensing of viruses by PRRs leads to the induction of type I interferons (TI-IFNs) and of pro-inflammatory cytokines such as 
interleukin-1 (IL-1) and tumour necrosis factor (TNF) via the activation of transcription factors; the induction of TI-IFNs requires the combined activation of NFKB and IFN regulatory factors (IRFs) $[13,14]$ whilst the regulation of pro-inflammatory genes is more

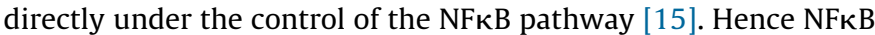
has a central role in controlling both the TI-IFN response and the inflammatory response, both of which are critical to anti-viral immunity.

The main poxviral PAMPs sensed by host PRRs, which cannot escape detection by viral evolution, are the virally-derived nucleic acids of genomes and transcripts present in the cytoplasm of infected cells, which are both chemically and/or compartmentally distinct from host RNA and DNA. In this review we describe the particular innate PRRs that have been linked to poxviral detection, and also the multiple strategies poxviruses have developed to suppress and avoid NFKB activation. Such anti-NFKB poxviral strategies target the NFKB complex directly, the proximal kinase activators of NFKB, and the upstream PRR and pro-inflammatory cytokine signalling pathways that converge on NFKB activation. The abundance of anti-NFKB strategies employed by poxviruses highlights the importance of NFKB activation in host anti-poxviral immunity.

\section{Fundamental mechanisms of NFKB activation}

The NFKB signalling system is one of the most ancient in animals and has retained a central role in immunity across the animal kingdom [16]. In mammals, the NFKB transcription factor complex consists of a homo- or heterodimeric association between constituent subunits RelA (p65), RelB, c-Rel, NFkB1 (p50) and NFkB2 (p52), via their N-terminal Rel Homology Domains (RHDs) [15]. The most commonly studied NFKB complex is p65-p50. In the absence of upstream activation, these dimeric complexes are preformed and sequestered in the cytoplasm in an inactive association with inhibitory family members of the IкB family. p50 and p52 are initially expressed as precursor proteins, p105 and p100 respectively, which themselves function as inhibitory processed into mature forms.

NFKB activation broadly occurs via either a canonical or a noncanonical pathway, both of which control the proteolysis of the inhibitory I $\mathrm{B}$ and $\mathrm{I} \mathrm{K} \mathrm{B}$ related proteins. The canonical pathway is activated by PRRs or pro-inflammatory cytokines such as IL-1 and TNF $\alpha$ leading to the activation of p65- or cRel-containing complexes [17], by proteasomal degradation of I $\mathrm{B} \alpha \alpha$ (Fig. 1). Thus PRR, IL-1 or TNF signalling activates the IкB kinase (IKK) complex composed of two catalytic subunits (IKK $\alpha$ and IKK $\beta$ ) and a regulatory subunit, NEMO (NFKB essential modulator or IKK $\gamma$ ) which phosphorylate both $\mathrm{p} 65$ and $І \kappa \mathrm{B} \alpha$. Phosphorylation of ІкB $\alpha$ induces its polyubiquitylation through the E3 ubiquitin ligase $\beta$ transducin repeat-containing protein $(\beta-\operatorname{TrCP})$, leading to proteasomal degradation of $I \kappa B$ at the proteasome. This releases the active $N F \kappa B$ dimer from IкB inhibition, allowing $N F \kappa B$ to translocate into the nucleus and induce expression of target genes. The non-canonical pathway, involving either $\mathrm{p} 105$ or $\mathrm{p} 100$, is activated by other TNF family members such as lymphotoxin $\beta 1$ and CD40 ligand [18]. This pathway activates IKK $\alpha$ to phosphoylate $\mathrm{p} 100$, causing it to be polyubuitylated by $\beta-\operatorname{TrCP}$ then partial proteolysed by the proteasome to produce mature p52. P52 then

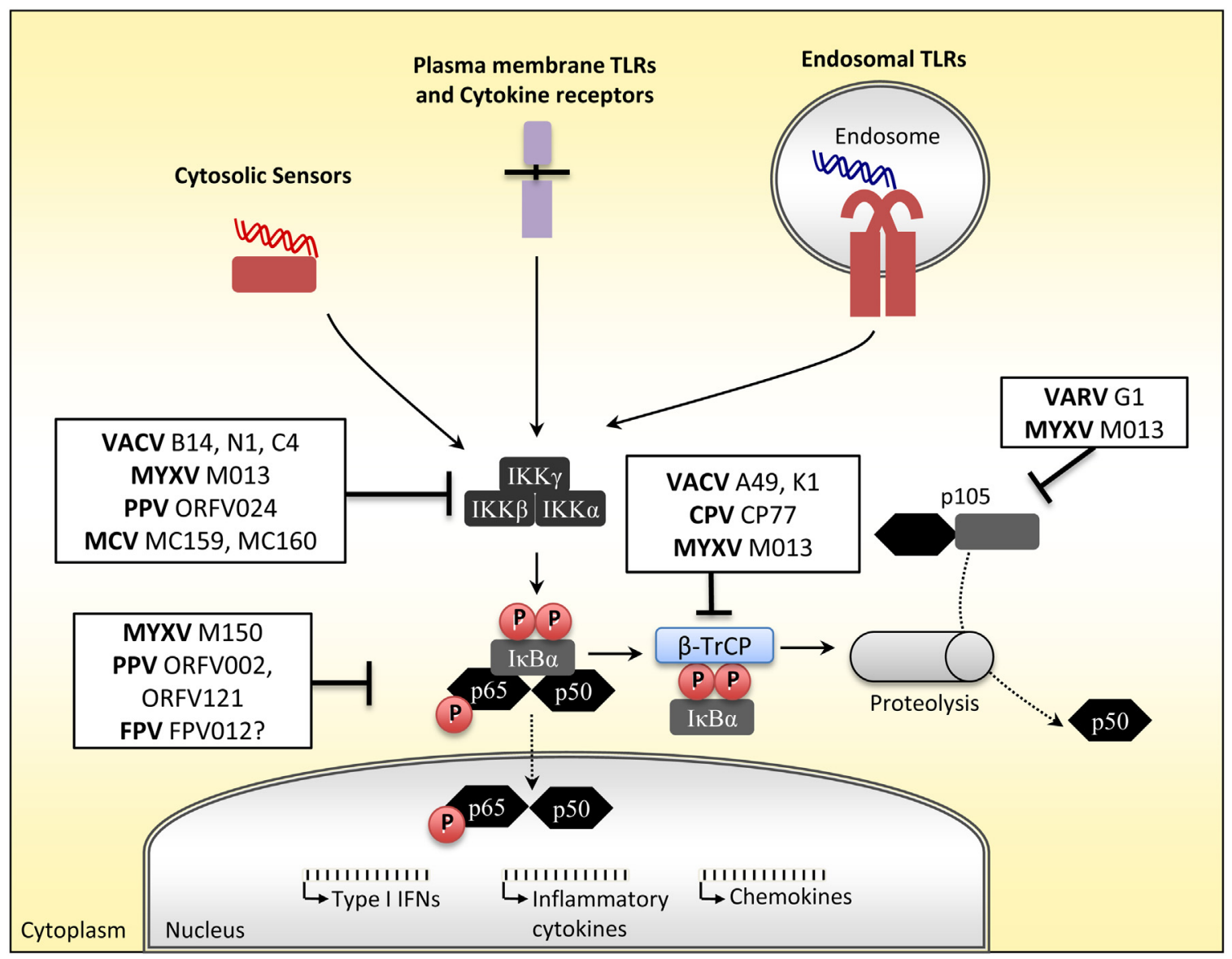

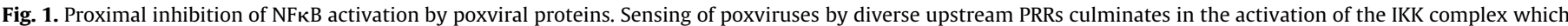

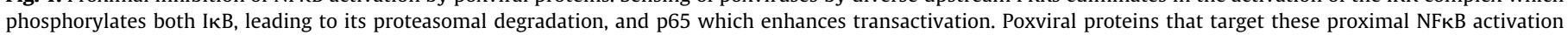
events are shown (see text for details). 
dimerizes predominantly with RelB to form an active NFкB complex which translocates into the nucleus [19]. Conversely, processing of $\mathrm{p} 105$ to produce the active, mature $\mathrm{p} 50$ subunit by the same mechanism is constitutive and does not require a stimulus. The activation of IKK $\beta$ by the canonical pathway causes IKK $\beta$ to phoshorylate p105 on the C-terminal destruction box which targets p105 for complete degradation and thus releases associated NFKB subunits to be phosphorylated by the canonical stimulus (Fig. 1).

\section{Direct targeting of NFKB and its proximal kinases by poxviruses}

Given that a diverse array of pathways that sense and respond to viral infection culminate in the activation of NFKB by IKKs, it might be presumed that the most efficient means of inhibiting NFKB from a virus point of view would be to directly target NFKB subunits or the proximal IKKs. It is therefore no surprise that this is the most common means by which poxviral inhibitors of this pathway exert their effect (Fig. 1).

Many Chordopoxviruses encode a proteins that are structurally similar to host $\mathrm{Bcl}-2$ proteins. These were likely derived from a common ancestral gene encoding a protein with the bcl-2 fold, which may have been captured from the host or could have independently evolved, but was then duplicated and functionally diversified over time [20] whilst retaining the same bcl-2 structure. The viral Bcl-2 family amino acid sequences are highly divergent even though they share the same overall bcl-2-like structure, and they interact with an impressively diverse range of different host partners to bring about the same biological outcome (as described here and in Section 4). This suggests that the bcl-2 fold may represent a stable structural scaffold upon which diverse interaction interfaces have evolved. Interestingly, several VACV proteins either proven or predicted to adopt the Bcl-2 structure have been shown to inhibit activation of NFKB by directly targeting the IKK complex. Such bcl-2-like IKK antagonists include B14, which directly interacts with and inhibits the activity of IKK $\beta$ [21], $\mathrm{N} 1$, which associates with the IKK complex [21], and C4 which inhibits NFKB at the level of IKK activation [22].

Yet another VACV protein which proximally targets NFKB activation is A49. This protein displays molecular mimicry since it contains a motif similar to that in ІкB $\alpha$ that is phosphorylated by IKK $\beta$ and subsequently binds to the E3 ligase $\beta$-TrCP. This allows A49 to preferentially bind $\beta-\operatorname{TrCP}$ and hence prevent it ubiqui-

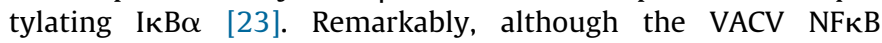
inhibitors described above would appear to be functioning redundantly, each inhibitor has been shown to contribute to virulence since viruses lacking just a single inhibitor are attenuated in vivo compared to wild type VACV [24].

All chordopoxviruses (with the notable exception of MCV and Crocodilepox virus) encode a family of proteins with multiple ankyrin repeats which, like the bcl-2 protein family described above, are involved in host-range and immunomodulation [25]. Some of these have also been shown to directly target NFкB, possibly by mimicking the ankyrin-repeats of the IкB family, which normally directly mediate the interaction of host ІкB proteins with the nuclear localization sequence of p65 and the dimerization domains of both p50 and p65 [26,27]. For example, VACV K1 contains such repeats and prevents $\mathrm{I} \kappa \mathrm{B} \alpha$ degradation [28]. CPV protein CP77 contains nine ankyrin repeats and an F-box like C-terminal domain that facilitate binding of CP77 to p65 and the $\mathrm{E} 3$ ubiquitin ligase complex that targets IкB, respectively. Both of these binding functions are essential for prevention of NFKB translocation into the nucleus suggesting that CP77 behaves like a surrogate IкB-like domain by binding $\mathrm{p} 65$ and $\beta-\operatorname{TrCP}$ to preventing proper translocation of NFKB [29]. CP77 might also target p65 for proteasomal degradation through these binding activities [30]. Other poxviral proteins demonstrated or suspected to directly interact with NFKB include: MYXV protein M150 which co-localises with NFKB and supresses inflammation [31]; VARV protein G1 which contains ankyrin repeats, is conserved in a number of orthopoxviruses (CPV, MYXV and ECTV) and has been shown to associate with p105 and block NFKB nuclear translocation [32]; MYXV protein M013 which also binds p105 to prevent its processing and subsequent NFKB activation [33].

Apart from the viral proteins described above which directly target IKKs or NFKB, other unique NFKB inhibitors exist that are more specific to certain vertebrate poxviruses, further emphasizing the need for diverse poxviruses to suppress NFкB activation in order to avoid elimination by host innate immunity. Thus ORFV024 protein from the parapoxvirus orf virus was shown to block IKK activation although the mechanism of its activity is not clear [34], while two other unique parapoxvirus proteins, ORFV002 and ORFV121, were recently shown to also inhibit NFKB activation. ORFV002 antagonized p65 phosphorylation by interfering with the association of p65 with the mitogen and stress-activated kinase-1 (MSK1) which prevented p65 recruiting the coactivator p300 to NFKB-dependent promoters, thus suppressing transactivation [35]. In contrast, ORFV121 interacts with p65 and prevents its nuclear translocation [36]. Very little is known about how the human-specific poxvirus MCV suppresses host innate immunity, yet the virus is known to encode two FLICE-like proteins (vFLIPs), MC159 and MC160, that antagonize NFKB. MC159 blocks IKK $\beta$ activation by interacting with IKK $\gamma$, while MC160 disrupts the IKK complex by stimulating IKK $\alpha$ degradation [37]. Given the density of NFKB inhibitors discovered in well-characterized poxviral genomes such as VACV, more poorly characterized poxviruses such as orf virus and MCV undoubtedly encode further NFKB inhibitors waiting to be discovered.

As noted above, activation of NFKB can occur through both PRRs and proinflammatory cytokine (IL-1 and TNF $\alpha$ ) signalling. In the following sections, we describe the role of PRRs (see Table 2) and proinflammatory cytokines in anti-poxviral innate immunity, and discuss ways in which poxviruses target and inhibit these signalling pathways, which provides a further layer of anti-NFKB poxviral strategies that operate upstream of those already described that act proximal to NFKB.

\section{TLRs link poxviral detection to NFKB activation}

TLRs are prototypical PRRs for PAMPs and DAMPs and are conserved across the animal kingdom, having retained a key role in immunity in diverse species [38]. Contexts whereby TLRs could sense the presence of poxviruses include when cells come into contact with extracellular virus particles, within the endosomes of phagocytotic macrophages and dendritic cells at sites of infection or after endocytosis and uncoating of virus during infection of multiple cell types.

TLR3 recognizes viral double stranded RNA (dsRNA) in endosomes and signals via homotypic interactions between Toll-IL-1R (TIR) domains through the adapter TIR-domain-containing adapter-inducing interferon- $\beta$ (TRIF), leading to recruitment and activation of receptor-interacting protein 1 (RIP1) and TNF receptor associated factor 6 (TRAF6), both of which are involved in transducing a signal to the IKK complex via activation the transforming growth factor beta-activated kinase 1 (TAK1) [38] (Fig. 2). TLR3 has been shown to respond to VACV but, rather than this response conferring protection on the host, TLR3 contributes to the immunopathology of the infection. Thus lower levels of VACV replication were observed in TLR3 ${ }^{-1-}$ mice compared to wild type animals, highlighting the critical balance between effective and excessive anti-viral responses [39]. Since the opposite result 
Table 2

PRRs implicated in poxviral detection leading to NFKB activation.

\begin{tabular}{|c|c|c|c|}
\hline & PRR & PAMP & Cell types examined (virus used) \\
\hline \multirow[t]{6}{*}{ TLRs } & TLR2 & $?$ & DC and T cells (VACV) [44] \\
\hline & TLR3 & dsRNA & Mouse, in vivo (VACV) [39] \\
\hline & TLR4 & $?$ & Mouse, in vivo (VACV) [40] \\
\hline & TLR7 & ssRNA & pDC (MYXV and heat killed VACV) [47] \\
\hline & TLR8 & G-rich NTs & $\mathrm{pDC}(\mathrm{VACV})[48]$ \\
\hline & TLR9 & dsDNA & pDC and cDC (myxoma) [50]; mouse in vivo and FL-DC (ECTV and MVA) [49] \\
\hline \multirow[t]{3}{*}{ RLRs } & RIG-I & PPP-RNA & Human fibroblasts and macrophages (MYXV) [69]; HeLa cells (VACV) [70] \\
\hline & MDA5 & dsRNA $>2000$ nts & HeLa cells (VACV) [70]; Hela cells (VACV RNA) [71]; THP1 (MVA) [72] \\
\hline & LGP2 & dsRNA & Murine fibroblasts (MVA) [73] \\
\hline \multirow[t]{2}{*}{ Other cytosolic sensors } & cGAS-STING & DNA & HEK293 cells (MVA) [85]; cDC and BMDC (MVA) [86] \\
\hline & Rad50-CARD9 & DNA & BMDCs (VACV) [90] \\
\hline
\end{tabular}

was seen in $\mathrm{TRIF}^{-1-}$ mice, this suggested a TRIF-dependent TLR other than TLR3 was actually protective in VACV infections [40]. Consistent with this, TLR4 which also uses TRIF for signalling, but is best known as the signalling receptor for bacterial LPS, was shown to be protective during VACV pulmonary infection although the mechanism for this remains unclear [40]. Since TLR4 can also sense respiratory syncytial virus (RSV) [41] and vesicular stomatitis virus (VSV) glycoproteins [42], it is possible that it plays a direct or cooperative role in sensing VACV surface glycoproteins in the same way. Alternatively, TLR4 may respond to DAMPs produced by a viral infection, as is the case for influenza virus [43]. TLR2 has also been shown to be important for sensing VACV and Ectromelia infection [44] though other authors find no role for this PRR in combating VACV infection in vivo [45].

Apart from TLR3, other endosomal TLRs have been linked to poxviral responses (Table 2): TLR9, the first DNA-sensing PRR to be discovered [46], senses unmethylated CpG DNA, whilst TLR7 and TLR8 sense ssRNA [38]. These endosomal TLRs activate NFKB via myeloid differentiation primary response gene 88 (MyD88) and TRAF6 [38] (Fig. 2). Poxvirus infection is detected by TLR7 [47], TLR8 [48] and TLR9 [49,50] in endosomes of conventional and plasmacytoid dendritic cells (cDCs and pDCs). Survival of mice after a lethal ECTV infection was critically reliant on TLR9, while MVA infection protected mice from ECTV in a manner dependent

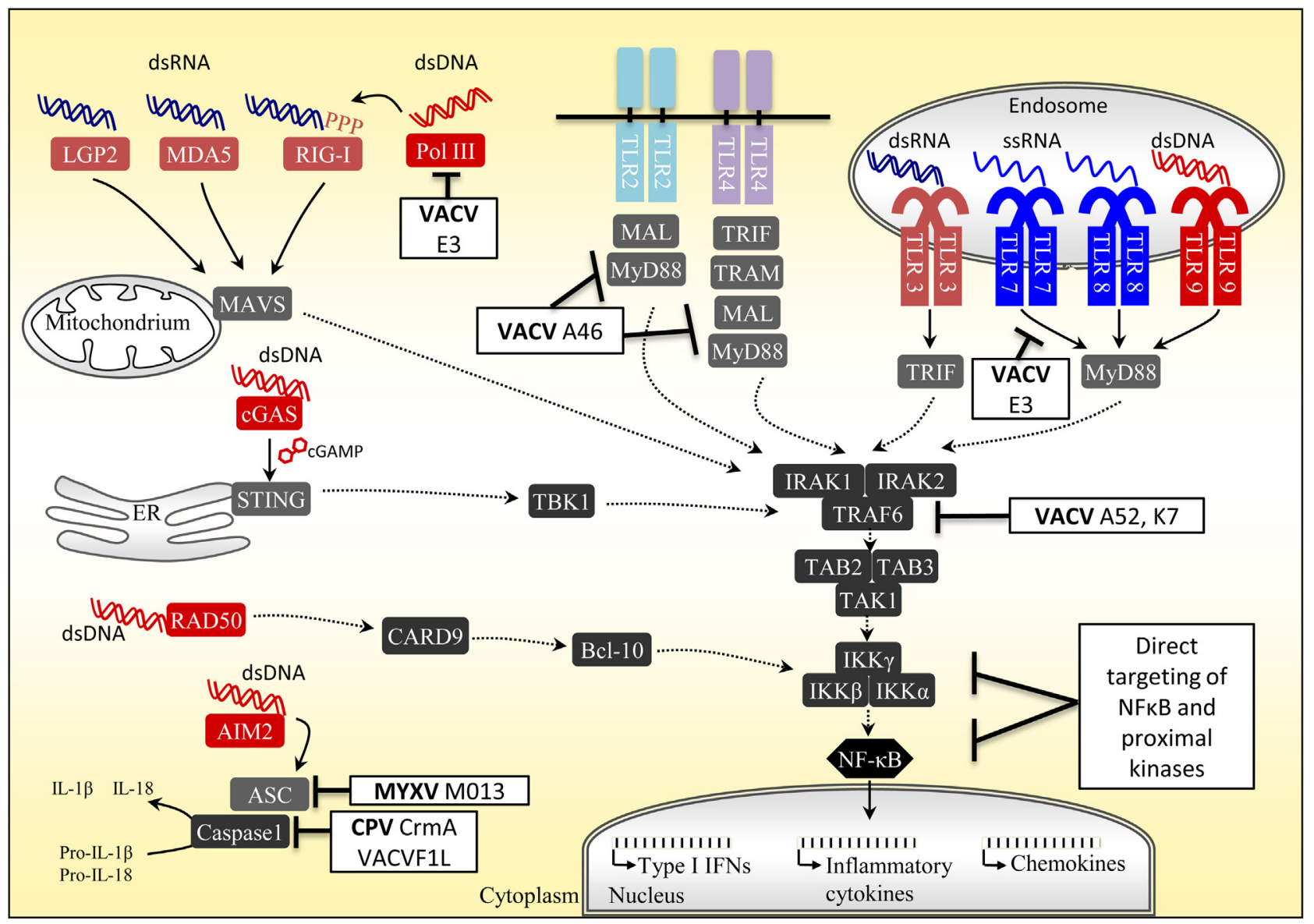

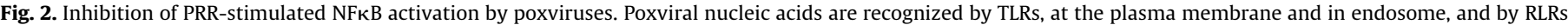

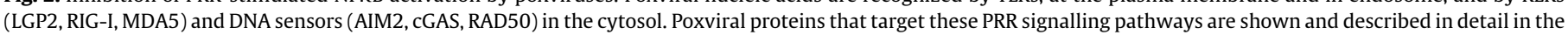
text. 
on TLR9 [49]. Recognition of poxvirus by TLR7 was proposed to involve detection of viral RNA transcripts [47], while surprisingly, TLR8-dependent responses were suggested to be mediated by recognition of poly(A)/T-rich poxviral DNA sequences [48]. Interestingly, although TLR3 and TLR9 are not normally expressed in skin [51,52], MCV-infected skin lesions exhibited increased expression of TLR3 and TLR9 in infected tissues, suggesting that these TLRs may be involved in the local host response to MCV in infected keratinocytes [52,53].

Consistent with the role of TLRs in sensing poxviruses, VACV has been shown to encode proteins that inhibit TLR signalling components, leading to suppression of TLR-dependent NFKB activation. The VACV TLR inhibitors A46 and A52 were initially identified as having sequence similarity to the TIR domain used by TLRs to signal to their adaptors [54], but were then proposed to be part of the poxviral bcl-2 family, which was confirmed by determination of their crystal structure [55,56]. Both were originally shown to inhibit TLR4-activated NFKB [54], while further work demonstrated that A52 inhibited all TLR pathways to NFKB activation by interacting with IL-1 receptor-associated kinase 2 (IRAK2), a finding that demonstrated a broad role for IRAK-2 in multiple TLR-stimulated NFKB activation pathways $[57,58]$. In contrast, A46 was shown to directly target TLR complexes by interacting with the TIR domain in both TLRs and the adaptor proteins MyD88, TRIF, MyD88-adapter-like (Mal) and TRIF-related adapter molecule (TRAM), and for TLR4 signalling to prevent adaptor recruitment to the TLR4 complex [59,60]. Indeed, inhibition of TLR4 could be reconstituted using a cell-permeable peptide (viral inhibitory peptide of TLR4, or VIPER) based on the surface of A46 that is required to disrupt TLR4 signalling to NFKB [61]. Yet another VACV bcl-2 protein, K7, which displays strong amino acid sequence similarity to A52, could also inhibit TLRstimulated NFKB activation by binding to IRAK2 [62].

Most of the VACV NFKB inhibitors described in the previous section that act close to NFKB itself were also shown to inhibit TLRstimulated NFкB. Thus, B14, C4, A49 and N1 were all shown to inhibit NFKB activation by a range of TLRs $[21,22,63]$. Further, the

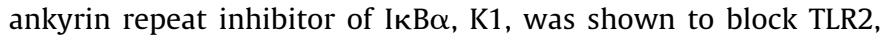
TLR4 and TLR9 stimulated NFKB in primary microglial cells [64]. Also, a recent screen of the avipoxvirus Fowlpox virus (FPV) identified an ankyrin repeat protein which blocked induction of chicken TI-IFN by the TLR3 ligand Poly (I:C), although the precise mechanism of its activity is still unclear [65]. However similar to other poxviral ankyrin repeat proteins, this FPV protein is likely to function by direct antagonism of NFKB.

Other poxviral proteins have unexpected roles in inhibiting TLRs. E3 is a key virulence factor for VACV, that has multiple activities in suppressing the host immune response, and contains an N-terminal Z-DNA/RNA binding motif as well as a C-terminal dsRNA binding domain [66]. The Z-DNA/RNA binding motif of E3 was shown to block TLR7 activation in pDCs [47]. This domain is not retained in the myxoma ortholog of E3, thus preventing it from evading TLR7, which suggests significant gain or loss of function between orthologous proteins in different poxviruses.

Altogether poxviruses are well equipped to suppress TLRstimulated NFKB activation which attests to an important, thought diverse, role for TLRs in mobilizing host innate immune responses towards poxviruses.

\section{NFKB activation by cytosolic detection of poxviral nucleic acids}

Despite the ability of TLRs to sense poxvirus infection, the attenuated MVA can still induce TI-IFNs in a TLR-independent fashion [67] suggesting additional PRRs can sense poxviral infection. Consistent with this, further PRRs that act in the cytosol and detect both poxviral RNA and DNA have been defined (Table 2). The cytosolic RNA receptors melanoma differentiation factor 5 (MDA5) and retinoic acid-inducible gene (RIG-I) detect long dsRNA and dsRNA with a $5^{\prime}$ triphosphate group respectively in the cytoplasm of cells infected with RNA viruses [68]. Upon activation, these RIG-I-like receptors (RLRs) engage the adaptor protein mitochondrial antiviral signalling (MAVS) which activates the IKK complex and subsequently NFKB (Fig. 2). Several recent reports demonstrate how poxviruses are also sensed by RLRs. For example, MYXV stimulates NFкB-dependent TNF $\alpha$ and TI-IFNs in primary human macrophages via RIG-I [69], VACV induces TI-IFN in a RIG-Iand MDA5-dependent manner in different cell types, and MVA induced IFN $\beta$ and IFN-dependent chemokines via MDA-5 and MAVS but not RIG-I in macrophages, suggesting both virus and cell-type differences in these responses [70-72]. A third RLR, LGP2 , has also been shown to be important for the upregulation of NFкB-dependent genes in response to VACV DNA [73]. MVA infection also causes increased cellular expression of the RLRs thus increasing the sensitivity of DCs to aberrant RNA [74]. The importance of RLRs in managing poxviral infection is reflected in the fact that it has been suggested that historical species-specific poxviral infection has played a role in positive selection of RLR families in different mammalian species [75]. A rationale for how cytosolic dsRNA PRRs are involved in detecting poxviruses is provided by the fact that poxviruses produce large amounts of dsRNA during an infection due to simultaneous transcription of both strands of the dsDNA viral genome [76]. In fact VACV E3, which binds dsRNA, was shown to block RLR-driven NFKBdependent gene induction in keratinocytes [77]. The requirement for RLRs in responding to poxviruses may also be partly explained by the RNA polymerase III intermediate system of cytosolic DNA detection whereby RNA polymerase III transcribes short RNA sequences from cytosolic AT-rich DNA that are direct ligands for RIG-I activation [78,79]. Interestingly, E3 can also antagonize ATrich DNA sensing via the RNA polymerase III system [80].

Although the physiological relevance for poxviruses of AT-rich dsDNA sensing by RNA polymerase III is unclear, as DNA viruses that reside in the cytosol poxviruses would be likely to be sensed by other recently described cytosolic DNA sensors that account for the ability of DNA in the cytosol, whether from viral infection or from aberrant host DNA metabolism, to activate transcription factors and induce TNF and TI-IFNs [81]. Such DNA sensors in many cases strongly activate IRF3, via a well-defined stimulator of IFN genes (STING)-Tank binding kinase 1 (TBK1)-IRF3 signalling axis whereas the DNA sensing cytosolic pathways to NFKB activation are still less clear. Both genetic and biochemical studies have demonstrated the importance of STING in signalling a response to DNA viruses in the cytoplasm though how STING itself is activated by upstream DNA sensors was unclear until recently [82]. A series of elegant studies then showed that cyclic-GMP-AMP (cGAMP) synthase (cGAS) is a DNA sensor upstream of STING, whose enzyme activity is stimulated by direct binding of DNA, leading to production of the novel second messenger cGAMP (reviewed in [83]). cGAMP is a direct ligand for STING, which is initially localized in the endoplasmic reticulum, but on binding cGAMP translocates to TBK1-containing membrane-bound compartments leading to IRF3 activation. Interestingly, a recent study demonstrated that, after infection of cells with MVA, cGAMP can diffuse through cellular gap junctions to activate the TI-IFN response in adjacent, uninfected cells, implying that the cGAS/STING system may directly prepare bystander cells for resistance to incoming poxviral infection [84,85]. The cGAS/STING system was also shown to sense MVA DNA in the cytoplasm of conventional DCs during infection [86]. The STING pathway has recently been proven to also activate $\mathrm{NF \kappa B}$, at least in fibroblasts, via TRAF6 [87]. Some number of papers have demonstrated that TI-IFN induction by VACV in some 
cell types requires cGAS $[85,86]$, although whether STING controls poxvirus-stimulated NFKB activation, as well as IRF3, remains to be determined. Whilst other viruses have been shown to target STING activation for immune evasion, no poxviral inhibitors of this system have yet been reported.

One cytosolic DNA sensing mechanism that exists in fibroblasts has been shown to be targeted by poxviruses for immune evasion: Ferguson et al. [88] showed that DNA-dependent protein kinase (DNA-PK) senses MVA, leading to STING-dependent IRF3 activation, which is subject to antagonism by the conserved VACV virulence factor $\mathrm{C} 16$, which directly bound the DNA-PK DNA sensing complex [89]. However, DNA-PK sensing of MVA did not lead to NFKB activation. A rare to date clear example of how cytosolic DNA sensing of poxviruses can cause NFKB activation was recently provided by Roth et al. [90]. This involved detection of cowpox and VACV DNA in murine DCs by direct binding to the DNA damage sensor Rad50, which somehow relocated from the nucleus to the cytoplasm in response to poxviral infection. Rad50 then recruited the innate immune signalling adaptor caspase-associated recruitment domain 9 (CARD9), which activated the IKK complex via Bcl-10, leading to induction of NFKB-dependent genes including TNF $\alpha$ and pro-IL-1 $\beta$ [90]. Importantly, Rad50/CARD9 sensing of poxviruses was also shown to operate in vivo.

In the future, based on what has been discovered for other PRR activators of NFKB, such as TLRs, one would expect that poxviral antagonists of DNA sensing pathways such as Rad50/CARD9 and cGAS will be discovered. As with other upstream activators of NFKB such as TLRs, some of the direct NFKB inhibitors (Section 3) would be predicted to block activation of NFKB through cGAS/STING and Rad50/Card9 sensing.

\section{Poxviral targeting of pro-inflammatory cytokines}

As described above, detection of poxviruses by PRRs leads to NFкB-dependent pro-inflammatory cytokine induction, which is a key host anti-viral protection mechanism. PRR stimulation causes intracellular expression of pro-IL-1 $\beta$, which needs to be processed by a caspase 1 -containing inflammasome into mature secreted IL-1 $\beta$. Absent in melanoma 2 (AIM2) is a PYRIN and HIN200 domaincontaining protein which forms an inflammasome that is activated by cytosolic DNA [91]. The HIN200 domain of AIM2 directly binds to dsDNA in the cytosol [92], leading to the recruitment of apoptotic speck protein (ASC) via the PYRIN domain, and subsequent recruitment and processing of pro-caspase 1 into caspase 1 [91] (Fig. 2). Importantly, the AIM2 inflammasome was shown to be required for VACV-stimulated IL-1 $\beta$ production in vivo. The NLRP3 inflammasome may also play a role in poxviral sensing since MVAinfected NALP3 knockout macrophages exhibited impaired processing of pro-IL1 $\beta$ [72]. Poxviral detection by inflammasome activation is targeted by a number of viral evasion strategies. The earliest reported inhibitor was CPV protein CrmA (and orthologs such as B13R in VACV) which inhibits IL1 $\beta$ processing by targeting Caspase 1 [93]. The MYXV protein M013, which was discussed earlier as a direct inhibitor of NFKB, is like many poxviral inhibitors multi-functional in that it also blocks caspase- 1 activation and proIL1 $\beta$ processing by targeting ASC [33]. Another inflammasome, NLRP1, is also targeted by poxviruses: the VACV Bcl-2 family member, F1L was shown to bind NLRP1 thereby limiting pro-IL-1 $\beta$ processing though the precise mechanism by which poxvirus infection activates this type of inflammasome is not yet clear [94].

Thus through PRR stimulation and inflammasome activation by poxviruses, IL-1 $\beta$ and TNF $\alpha$ are produced by the host. This leads to autocrine and paracrine stimulation of distinct pathways through the IL1 and TNF receptors which activates a second wave of NFKB activation [95,96]. Pro-inflammatory cytokine stimulation of $\mathrm{NF \kappa B}$ activation induces a wide range of chemokines, adhesion molecules and further pro-inflammatory cytokines that cause local inflammation and fever, facilitating virus clearance and long-term adaptive immunity.

Both IL-1 and TNF $\alpha$ signalling culminate in the activation of the IKK complex and of NFKB, but by distinct upstream receptorproximal events (Fig. 3). For IL-1, binding to the IL1 receptor complex (containing the IL-1R and the IL-1R accessory protein) recruits the adapter MyD88, leading to the activation of a similar signalling axis as used by MyD88-dependent TLRs involving IRAK2, TRAK6 and TAK1. Thus the VACV inhibitors of TLR-stimulated NFKB activation, A46 and A52, also antagonize IL-1 signalling, which likely contributes to their role in virulence [57,59]. TNF binding to the TNF receptor causes receptor trimerization and recruits TRADD which in turn recruits TRAF2, cIAPs and receptorinteracting protein kinase (RIPK1). The IKKs are recruited to this complex and activate NFKB (Fig. 3). Both IL-1 and TNF-stimulated $\mathrm{NF \kappa B}$ activation are targeted by most if not all of the proximal NFKB inhibitors described in Section 3.

Apart from inhibiting intracellular signalling to NFKB by IL-1 and TNF $\alpha$, poxviruses also target these cytokines by expressing poxvirally-encoded secreted binding proteins and receptors from infected cells, which inhibit the cell surface binding of the IL-1 family (IL-1 $\beta$ and IL-18) and of the TNF family (TNF $\alpha$, Lymphotoxin- $\alpha$, CD153) [97]. Some poxvirally-encoded TNF-binding proteins resemble a soluble TNFR (vTNFRs) with varying degrees of ligand specificity and affinity [98] while some do not directly resemble the TNFR and are therefore referred to as 'TNF binding proteins' (vTNF-BPs) [99]. For IL-1, unlike the cellular receptor that binds both IL- $1 \alpha$ and IL-1 $\beta$, the poxviral soluble IL-1 receptor of VACV and CPXV binds only IL- $1 \beta$, which is the main form produced and processed in poxvirus-infected cells.

TNF is particularly important in controlling MCV infections as evidenced by the exacerbation and spread of lesions in patients taking anti-TNF therapy [7], which is reflected in the immune

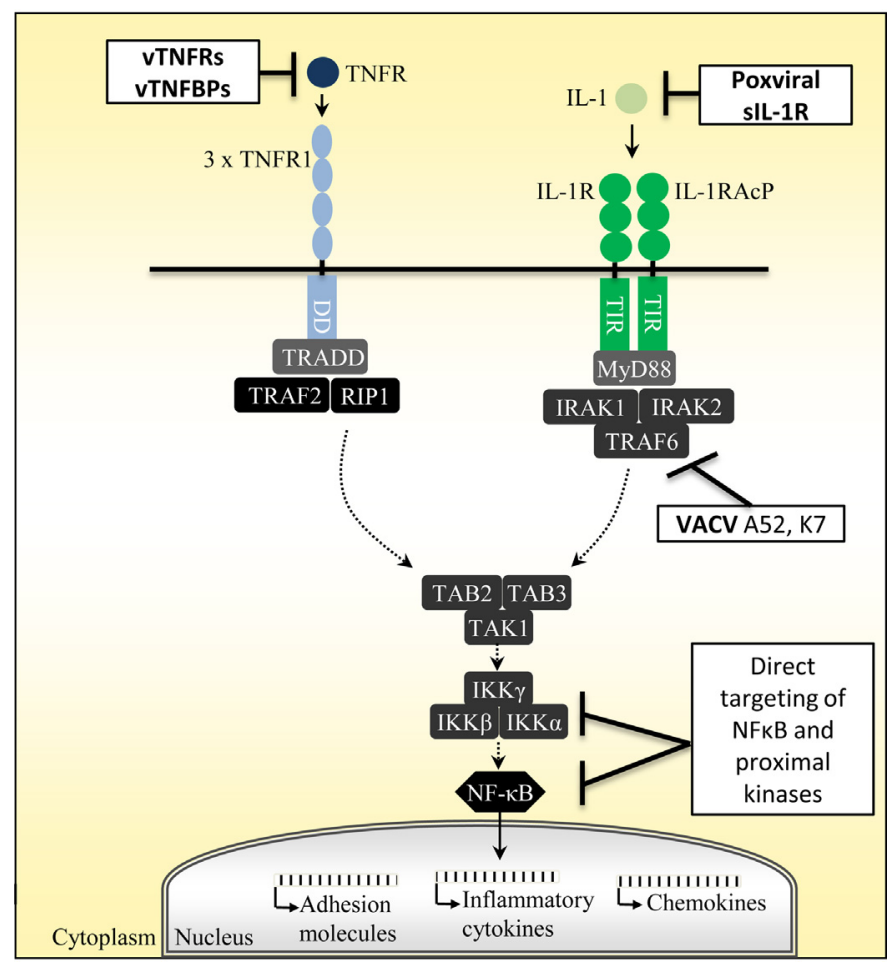

Fig. 3. Poxviral targeting of pro-inflammatory cytokine signalling to NFKB. Poxviruses target IL-1 and TNF $\alpha$ function by encoding both secreted extracellular cytokine binding proteins, and intracellular inhibitors of signal transduction (see text for details). 
evasion proteins known to be expressed by MCV: MC159 and MC160 block TNF receptor induced apoptosis and NFKB activation by distinct mechanisms [37]. As yet only 5 out of 182 MCV ORFs have been shown to possess immunomodulatory function and these all use strategies not employed by other poxviruses. Given the ability of this human poxvirus to block the local immune response to its presence and the density of such ORFs in better characterized poxviruses like VACV, further study of this virus would undoubtedly reveal many more.

Overall one can surmise the importance of IL1 and TNF in poxviral infections by the number of genes and strategies poxviruses devote to blocking their production, signalling and pro-inflammatory activity. Such strategies include inhibiting their induction and processing by blocking PRR signalling and inflammasome activation, soaking up IL1 and TNF through the production of secreted binding proteins, blocking their signal transduction to $\mathrm{NF \kappa B}$, and also preventing the activity of IL1- and TNF-induced genes, such as chemokines, with viral chemokine binding proteins.

\section{Concluding remarks}

We have described the current understanding of the ways in which poxviruses trigger anti-viral immunity to activate NFKB and the many different non-redundant ways in which they target and inhibit its activation. Poxviruses are particularly adept at blocking NFKB at many levels, although many of the known NFKB antagonists function proximal to the IKK complex or to NFKB itself. This allows effective inhibition of multiple PRR and cytokine signalling pathways that converge on NFKB by a small repertoire of viral proteins. However poxviruses invariably evolve multiple inhibitors of NFKB which do not seem to act redundantly based on data from in vivo challenges of animals with viruses lacking individual inhibitors. The importance of targeting NFKB activation in multiple ways, frequently on the same pathways and in the same cell, has not been clear. One possibility is that the complexity of upstream activating networks stimulated by poxvirus infection which lead to this key anti-viral and inflammatory transcription factor being activated makes distinct inhibitors necessary to ensure effective inhibition of every poxvirus sensing and activation pathway. In addition, the crucial importance of NFKB activation to an effective anti-viral response may have exerted evolutionary pressure on the host to diversify the processes of activation of this transcription factor in order to protect it against single, modular mechanisms of viral inhibition. It would be interesting to assess the combinatorial activity of these inhibitors to determine if their combined activity is required to fully cut through the "checks and balances' of this pathway in vivo.

A recent study demonstrated that when all the known NFкB inhibitors were knocked out in VACV the virus was still able to inhibit NFKB-induced gene expression. This suggests other inhibitors remain to be found even in this relatively well characterized virus [100]. It is sensible to assume that other poxviruses may encode a similar amount of NFKB inhibitors that remain to be found. For example, only two have been discovered in the understudied human-specific poxvirus MCV which has an unsurpassed ability to inhibit local inflammation. Since MCV, more than any other poxvirus studied, is specifically adapted to target human innate immunity, it will be informative to elucidate further MCV strategies of NFKB antagonism, which may yield unique insights into the role of human NFKB in inflammation and immunity.

\section{Acknowledgements}

This work was supported by Science Foundation Ireland grant 11/PI/1056 (to A.G.B.) and Marie Curie Intra-European Fellowship no. 332057 (to G.B.).

\section{References}

[1] Tulman ER, Afonso CL, Lu Z, Zsak L, Kutish GF, Rock DL. The genome of canarypox virus. J Virol 2004;78:353-66.

[2] Brunetti CR, Amano H, Ueda Y, Qin J, Miyamura T, Suzuki T, et al. Complete genomic sequence and comparative analysis of the tumorigenic poxvirus Yaba monkey tumor virus. J Virol 2003;77:13335-47.

[3] Xing K, Deng R, Wang J, Feng J, Huang M, Wang X. Genome-based phylogeny of poxvirus. Intervirology 2006;49:207-14.

[4] Haller SL, Peng C, McFadden G, Rothenburg S. Poxviruses and the evolution of host range and virulence. Infect Genet Evol: J Mol Epidemiol Evol Genet Infect Dis 2014;21:15-40.

[5] McFadden G. Poxvirus tropism. Nat Rev Microbiol 2005;3:201-13.

[6] Moss B. Poxvirus entry and membrane fusion. Virology 2006;344:48-54.

[7] Chen X, Anstey AV, Bugert JJ. Molluscum contagiosum virus infection. Lancet Infect Dis 2013;13:877-88.

[8] Lefkowitz EJ, Wang C, Upton C. Poxviruses: past, present and future. Virus Res 2006;117:105-18.

[9] Ball LA. High-frequency homologous recombination in vaccinia virus DNA. J Virol 1987;61:1788-95.

[10] Esteban DJ, Hutchinson AP. Genes in the terminal regions of orthopoxvirus genomes experience adaptive molecular evolution. BMC Genomics $2011 ; 12: 261$.

[11] Elde NC, Child SJ, Eickbush MT, Kitzman JO, Rogers KS, Shendure J, et al. Poxviruses deploy genomic accordions to adapt rapidly against host antiviral defenses. Cell 2012;150:831-41.

[12] Tsai SY, Segovia JA, Chang TH, Morris IR, Berton MT, Tessier PA, et al. DAMP molecule S100A9 acts as a molecular pattern to enhance inflammation during influenza A virus infection: role of DDX21-TRIF-TLR4-MyD88 pathway. PLoS Pathog 2014;10:e1003848.

[13] Kim TK, Maniatis T. The mechanism of transcriptional synergy of an in vitro assembled interferon-beta enhanceosome. Mol Cell 1997:1:119-29.

[14] Marie I, Durbin JE, Levy DE. Differential viral induction of distinct interferonalpha genes by positive feedback through interferon regulatory factor-7. EMBO J 1998;17:6660-9.

[15] Lawrence T. The nuclear factor NF-kappaB pathway in inflammation. Cold Spring Harb Perspect Biol 2009;1:a001651.

[16] Friedman R, Hughes AL. Molecular evolution of the NF-kappaB signaling system. Immunogenetics 2002;53:964-74.

[17] Karin M, Ben-Neriah Y. Phosphorylation meets ubiquitination: the control of NF-[kappa]B activity. Annu Rev Immunol 2000;18:621-63.

[18] Senftleben U, Cao Y, Xiao G, Greten FR, Krahn G, Bonizzi G, et al. Activation by IKKalpha of a second, evolutionary conserved, NF-kappa B signaling pathway. Science 2001;293:1495-9.

[19] Beinke S, Ley SC. Functions of NF-kappaB1 and NF-kappaB2 in immune cell biology. Biochem J 2004;382:393-409.

[20] Gonzalez JM, Esteban M. A poxvirus Bcl-2-like gene family involved in regulation of host immune response: sequence similarity and evolutionary history. Virol J 2010;7:59.

[21] DiPerna G, Stack J, Bowie AG, Boyd A, Kotwal G, Zhang Z, et al. Poxvirus protein N1L targets the I-kappaB kinase complex, inhibits signaling to NFkappaB by the tumor necrosis factor superfamily of receptors, and inhibits NF-kappaB and IRF3 signaling by toll-like receptors. J Biol Chem 2004;279: 36570-36578.

[22] Ember SW, Ren H, Ferguson BJ, Smith GL. Vaccinia virus protein C4 inhibits NF-kappaB activation and promotes virus virulence. J Gen Virol 2012;93:2098-108.

[23] Mansur DS, Maluquer de Motes C, Unterholzner L, Sumner RP, Ferguson BJ, Ren $\mathrm{H}$, et al. Poxvirus targeting of E3 ligase beta-TrCP by molecular mimicry: a mechanism to inhibit NF-kappaB activation and promote immune evasion and virulence. PLoS Pathog 2013;9:e1003183.

[24] Smith GL, Benfield CT, Maluquer de Motes C, Mazzon M, Ember SW, Ferguson BJ, et al. Vaccinia virus immune evasion: mechanisms, virulence and immunogenicity. J Gen Virol 2013;94:2367-92.

[25] Sonnberg S, Fleming SB, Mercer AA. Phylogenetic analysis of the large family of poxvirus ankyrin-repeat proteins reveals orthologue groups within and across chordopoxvirus genera. J Gen Virol 2011;92:2596-607.

[26] Huxford T, Huang DB, Malek S, Ghosh G. The crystal structure of the IkappaBalpha/NF-kappaB complex reveals mechanisms of NF-kappaB inactivation. Cell 1998;95:759-70.

[27] Jacobs MD, Harrison SC. Structure of an IkappaBalpha/NF-kappaB complex. Cell 1998;95:749-58.

[28] Shisler JL, Jin XL. The vaccinia virus K1L gene product inhibits host NF-kappaB activation by preventing IkappaBalpha degradation. J Virol 2004;78: 3553-3560.

[29] Chang SJ, Hsiao JC, Sonnberg S, Chiang CT, Yang MH, Tzou DL, et al. Poxvirus host range protein $\mathrm{CP} 77$ contains an F-box-like domain that is necessary to suppress NF-kappaB activation by tumor necrosis factor alpha but is independent of its host range function. J Virol 2009;83:4140-52.

[30] Alzhanova D, Fruh K. Modulation of the host immune response by cowpox virus. Microb Infect Inst Pasteur 2010;12:900-9.

[31] Camus-Bouclainville C, Fiette L, Bouchiha S, Pignolet B, Counor D, Filipe C, et al. A virulence factor of myxoma virus colocalizes with NF-kappaB in the nucleus and interferes with inflammation. J Virol 2004;78:2510-6.

[32] Mohamed MR, Rahman MM, Lanchbury JS, Shattuck D, Neff C, Dufford M et al. Proteomic screening of variola virus reveals a unique NF-kappaB 
inhibitor that is highly conserved among pathogenic orthopoxviruses. Proc Natl Acad Sci USA 2009:106:9045-50.

[33] Rahman MM, Mohamed MR, Kim M, Smallwood S, McFadden G. Co-regulation of NF-kappaB and inflammasome-mediated inflammatory responses by myxoma virus pyrin domain-containing protein M013. PLoS Pathog 2009:5:e1000635.

[34] Diel DG, Delhon G, Luo S, Flores EF, Rock DL. A novel inhibitor of the NF$\{$ kappa\}B signaling pathway encoded by the parapoxvirus orf virus. J Virol 2010;84:3962-73.

[35] Ning Z, Zheng Z, Hao W, Duan C, Li W, Wang Y, et al. The N terminus of orf virus-encoded protein 002 inhibits acetylation of NF-kappaB p65 by preventing Ser(276) phosphorylation. PLOS ONE 2013;8:e58854.

[36] Diel DG, Luo S, Delhon G, Peng Y, Flores EF, Rock DL. Orf virus ORFV121 encodes a novel inhibitor of NF-kappaB that contributes to virus virulence. J Virol 2011;85:2037-49.

[37] Shisler JL. Viral and cellular FLICE-inhibitory proteins: a comparison of their roles in regulating intrinsic immune responses. J Virol 2014;88:6539-41.

[38] O'Neill LA, Golenbock D, Bowie AG. The history of toll-like receptors redefining innate immunity. Nat Rev Immunol 2013;13:453-60.

[39] Hutchens M, Luker KE, Sottile P, Sonstein J, Lukacs NW, Nunez G, et al. TLR3 increases disease morbidity and mortality from vaccinia infection. J Immunol 2008;180:483-91.

[40] Hutchens MA, Luker KE, Sonstein J, Nunez G, Curtis JL, Luker GD. Protective effect of toll-like receptor 4 in pulmonary vaccinia infection. PLoS Pathog 2008; 4:e1000153

[41] Kurt-Jones EA, Popova L, Kwinn L, Haynes LM, Jones LP, Tripp RA, et al. Pattern recognition receptors TLR4 and CD14 mediate response to respiratory syncytial virus. Nat Immunol 2000;1:398-401

[42] Georgel P, Jiang Z, Kunz S, Janssen E, Mols J, Hoebe K, et al. Vesicular stomatitis virus glycoprotein $\mathrm{G}$ activates a specific antiviral toll-like receptor 4-dependent pathway. Virology 2007;362:304-13.

[43] Shirey KA, Lai W, Scott AJ, Lipsky M, Mistry P, Pletneva LM, et al. The TLR4 antagonist Eritoran protects mice from lethal influenza infection. Nature 2013:497:498-502.

[44] O‘Gorman WE, Sampath P, Simonds EF, Sikorski R, O‘Malley M, Krutzik PO, et al. Alternate mechanisms of initial pattern recognition drive differentia immune responses to related poxviruses. Cell Host Microbe 2010;8:174-85.

[45] Davies ML, Sei JJ, Siciliano NA, Xu RH, Roscoe F, Sigal LJ, et al. MyD88 dependent immunity to a natural model of vaccinia virus infection does not involve toll-like receptor 2. J Virol 2014;88:3557-67.

[46] Hemmi H, Takeuchi O, Kawai T, Kaisho T, Sato S, Sanjo H, et al. A toll-like receptor recognizes bacterial DNA. Nature 2000;408:740-5.

[47] Cao H, Dai P, Wang W, Li H, Yuan J, Wang F, et al. Innate immune response of human plasmacytoid dendritic cells to poxvirus infection is subverted by vaccinia E3 via its Z-DNA/RNA binding domain. PLOS ONE 2012;7:e36823.

[48] Martinez J, Huang X, Yang Y. Toll-like receptor 8-mediated activation of murine plasmacytoid dendritic cells by vaccinia viral DNA. Proc Natl Acad Sci USA 2010:107:6442-7.

[49] Samuelsson C, Hausmann J, Lauterbach H, Schmidt M, Akira S, Wagner H, et al Survival of lethal poxvirus infection in mice depends on TLR9, and therapeutic vaccination provides protection. J Clin Investig 2008;118: 1776-1784.

[50] Dai P, Cao H, Merghoub T, Avogadri F, Wang W, Parikh T, et al. Myxoma virus induces type I interferon production in murine plasmacytoid dendritic cells via a TLR9/MyD88-, IRF5/IRF7-, and IFNAR-dependent pathway. J Virol 2011;85:10814-25.

[51] Kawai K, Shimura H, Minagawa M, Ito A, Tomiyama K, Ito M. Expression of functional toll-like receptor 2 on human epidermal keratinocytes. J Dermatol Sci 2002;30:185-94

[52] Ku JK, Kwon HJ, Kim MY, Kang H, Song PI, Armstrong CA, et al. Expression of toll-like receptors in verruca and Molluscum contagiosum. J Kor Med Sc 2008:23:307-14

[53] Seleit I, Bakry OA, Abdou AG, Dawoud NM. Immunohistochemical expression of aberrant Notch-1 signaling in vitiligo: an implication for pathogenesis. Ann Diagn Pathol 2014:18:117-24.

[54] Bowie A, Kiss-Toth E, Symons JA, Smith GL, Dower SK, O‘Neill LA. A46R and A52R from vaccinia virus are antagonists of host IL-1 and toll-like receptor signaling. Proc Natl Acad Sci USA 2000;97:10162-67.

[55] Fedosyuk S, Grishkovskaya I, de Almeida Ribeiro Jr E, Skern T. Characterization and structure of the vaccinia virus NF-kappaB antagonist A46. J Biol Chem 2014;289:3749-62.

[56] Graham SC, Bahar MW, Cooray S, Chen RA, Whalen DM, Abrescia NG, et al. Vaccinia virus proteins A52 and B14 share a Bcl-2-like fold but have evolved to inhibit NF-kappaB rather than apoptosis. PLoS Pathog 2008;4:e1000128.

[57] Harte MT, Haga IR, Maloney G, Gray P, Reading PC, Bartlett NW, et al. The poxvirus protein $\mathrm{A} 52 \mathrm{R}$ targets toll-like receptor signaling complexes to suppress host defense. J Exp Med 2003;197:343-51.

[58] Keating SE, Maloney GM, Moran EM, Bowie AG. IRAK-2 participates in multiple toll-like receptor signaling pathways to NFkappaB via activation of TRAF6 ubiquitination. J Biol Chem 2007;282:33435-43.

[59] Stack J, Haga IR, Schroder M, Bartlett NW, Maloney G, Reading PC, et al. Vaccinia virus protein A46R targets multiple toll-like-interleukin-1 recepto adaptors and contributes to virulence. J Exp Med 2005;201:1007-18.

[60] Stack J, Bowie AG. Poxviral protein A46 antagonizes toll-like receptor 4 signaling by targeting BB loop motifs in Toll-IL-1 receptor adaptor protein to disrupt receptor: adaptor interactions. J Biol Chem 2012;287:22672-82.
[61] Lysakova-Devine T, Keogh B, Harrington B, Nagpal K, Halle A, Golenbock DT, et al. Viral inhibitory peptide of TLR4 a peptide derived from vaccinia protein A46, specifically inhibits TLR4 by directly targeting MyD88 adaptor-like and TRIF-related adaptor molecule. J Immunol 2010;185:4261-71.

[62] Schroder M, Baran M, Bowie AG. Viral targeting of DEAD box protein 3 reveals its role in TBK1/IKKepsilon-mediated IRF activation. EMBO J 2008;27: 2147-2157

[63] Chen RA, Ryzhakov G, Cooray S, Randow F, Smith GL. Inhibition of IkappaB kinase by vaccinia virus virulence factor B14. PLoS Pathog 2008;4:e22.

[64] Aravalli RN, Hu S, Lokensgard JR. Inhibition of toll-like receptor signaling in primary murine microglia. J Neuroimmune Pharmacol: Off J Soc Neuroimmune Pharmacol 2008;3:5-11.

[65] Laidlaw SM, Robey R, Davies M, Giotis ES, Ross C, Buttigieg K, et al. Genetic screen of a mutant poxvirus library identifies an ankyrin repeat protein involved in blocking induction of avian type I interferon. J Virol 2013;87:5041-52.

[66] Brandt TA, Jacobs BL. Both carboxy- and amino-terminal domains of the vaccinia virus interferon resistance gene, E3L, are required for pathogenesis in a mouse model. J Virol 2001;75:850-6.

[67] Waibler Z, Anzaghe M, Ludwig H, Akira S, Weiss S, Sutter G, et al. Modified vaccinia virus Ankara induces toll-like receptor-independent type I interferon responses. J Virol 2007;81:12102-10.

[68] Loo YM, Gale Jr M. Immune signaling by RIG-I-like receptors. Immunity 2011;34:680-92

[69] Wang F, Gao X, Barrett JW, Shao Q, Bartee E, Mohamed MR, et al. RIG-I mediates the co-induction of tumor necrosis factor and type I interferon elicited by myxoma virus in primary human macrophages. PLoS Pathog 2008;4:e1000099

[70] Myskiw C, Arsenio J, Booy EP, Hammett C, Deschambault Y, Gibson SB, et al. RNA species generated in vaccinia virus infected cells activate cell typespecific MDA5 or RIG-I dependent interferon gene transcription and PKR dependent apoptosis. Virology 2011;413:183-93.

171] Pichlmair A, Schulz O, Tan CP, Rehwinkel J, Kato $H$, Takeuchi O, et al Activation of MDA5 requires higher-order RNA structures generated during virus infection. J Virol 2009;83:10761-69

[72] Delaloye J, Roger T, Steiner-Tardivel QG, Le Roy D, Knaup Reymond M, Akira S, et al. Innate immune sensing of modified vaccinia virus Ankara (MVA) is mediated by TLR2-TLR6, MDA-5 and the NALP3 inflammasome. PLoS Pathog 2009;5:e1000480

[73] Pollpeter D, Komuro A, Barber GN, Horvath CM. Impaired cellular responses to cytosolic DNA or infection with Listeria monocytogenes and vaccinia virus in the absence of the murine LGP2 protein. PLoS ONE 2011;6:e18842.

[74] Guerra S, Najera JL, Gonzalez JM, Lopez-Fernandez LA, Climent N, Gatell JM, et al. Distinct gene expression profiling after infection of immature human monocyte-derived dendritic cells by the attenuated poxvirus vectors MVA and NYVAC. J Virol 2007;81:8707-21

[75] Lemos de Matos A, McFadden G, Esteves PJ. Evolution of viral sensing RIG-Ilike receptor genes in Leporidae genera Oryctolagus, Sylvilagus, and Lepus. Immunogenetics 2014;66:43-52.

[76] Weber F, Wagner V, Rasmussen SB, Hartmann R, Paludan SR. Double-stranded RNA is produced by positive-strand RNA viruses and DNA viruses but not in detectable amounts by negative-strand RNA viruses. J Virol 2006;80:5059-64

77] Deng L, Dai P, Parikh T, Cao H, Bhoj V, Sun Q, et al. Vaccinia virus subverts a mitochondrial antiviral signaling protein-dependent innate immune response in keratinocytes through its double-stranded RNA binding protein, E3. J Virol 2008;82:10735-46.

[78] Ablasser A, Bauernfeind F, Hartmann G, Latz E, Fitzgerald KA, Hornung V. RIG I-dependent sensing of poly $(\mathrm{dA}: \mathrm{dT})$ through the induction of an RNA polymerase III-transcribed RNA intermediate. Nat Immunol 2009;10:1065-72.

79] Chiu YH, Macmillan JB, Chen ZJ. RNA polymerase III detects cytosolic DNA and induces type I interferons through the RIG-I pathway. Cell 2009:138: 576-591.

[80] Valentine R, Smith GL. Inhibition of the RNA polymerase III-mediated dsDNAsensing pathway of innate immunity by vaccinia virus protein E3. J Gen Virol 2010;91:2221-9

[81] Paludan SR, Bowie AG. Immune sensing of DNA. Immunity 2013;38:870-80.

[82] Burdette DL, Vance RE. STING and the innate immune response to nucleic acids in the cytosol. Nat Immunol 2013;14:19-26.

[83] Cai X, Chiu YH, Chen ZJ. The cGAS-cGAMP-STING pathway of cytosolic DNA sensing and signaling. Mol Cell 2014;54:289-96.

[84] Ablasser A, Goldeck M, Cavlar T, Deimling T, Witte G, Rohl I, et al cGAS produces a $2^{\prime}-5^{\prime}$-linked cyclic dinucleotide second messenger that activates STING. Nature 2013;498:380-4

[85] Ablasser A, Schmid-Burgk JL, Hemmerling I, Horvath GL, Schmidt T, Latz E, et al. Cell intrinsic immunity spreads to bystander cells via the intercellular transfer of cGAMP. Nature 2013;503:530-4

[86] Dai P, Wang W, Cao H, Avogadri F, Dai L, Drexler I, et al. Modified vaccinia virus Ankara triggers type I IFN production in murine conventional dendritic cells via a cGAS/STING-mediated cytosolic DNA-sensing pathway. PLoS Pathog 2014;10:e1003989.

87] Abe T, Barber GN. Cytosolic-DNA-mediated, STING-dependent proinflammatory gene induction necessitates canonical NF-kappaB activation through TBK1. J Virol 2014;88:5328-41

[88] Ferguson BJ, Mansur DS, Peters NE, Ren H, Smith GL. DNA-PK is a DNA sensor for IRF-3-dependent innate immunity. eLife 2012;1:e00047. 
[89] Peters NE, Ferguson BJ, Mazzon M, Fahy AS, Krysztofinska E, Arribas-Bosacoma R, et al. A mechanism for the inhibition of DNA-PK-mediated DNA sensing by a virus. PLoS Pathog 2013;9:e1003649.

[90] Roth S, Rottach A, Lotz-Havla AS, Laux V, Muschaweckh A, Gersting SW, et al. Rad50-CARD9 interactions link cytosolic DNA sensing to IL-1beta production. Nat Immunol 2014;15:538-45.

[91] Hornung V, Ablasser A, Charrel-Dennis M, Bauernfeind F, Horvath G, Caffrey DR, et al. AIM2 recognizes cytosolic dsDNA and forms a caspase-1-activating inflammasome with ASC. Nature 2009;458:514-8.

[92] Jin T, Perry A, Jiang J, Smith P, Curry JA, Unterholzner L, et al. Structures of the HIN domain: DNA complexes reveal ligand binding and activation mechanisms of the AIM2 inflammasome and IFI16 receptor. Immunity 2012;36:561-71.

[93] Ray CA, Black RA, Kronheim SR, Greenstreet TA, Sleath PR, Salvesen GS, et al. Viral inhibition of inflammation: cowpox virus encodes an inhibitor of the interleukin-1 beta converting enzyme. Cell 1992;69:597-604.

[94] Gerlic M, Faustin B, Postigo A, Yu EC, Proell M, Gombosuren N, et al. Vaccinia virus F1L protein promotes virulence by inhibiting inflammasome activation. Proc Natl Acad Sci USA 2013;110:7808-13.

[95] Dinarello CA. Interleukin-1 in the pathogenesis and treatment of inflammatory diseases. Blood 2011;117:3720-32.

[96] Silke J. The regulation of TNF signalling: what a tangled web we weave. Curr Opin Immunol 2011;23:620-6.

[97] Seet BT, Johnston JB, Brunetti CR, Barrett JW, Everett H, Cameron C, et al. Poxviruses and immune evasion. Annu Rev Immunol 2003;21:377-423.

[98] Gileva IP, Nepomnyashchikh TS, Antonets DV, Lebedev LR, Kochneva GV, Grazhdantseva AV, et al. Properties of the recombinant TNF-binding proteins from variola, monkeypox, and cowpox viruses are different. Biochim Biophys Acta 2006;1764:1710-8.

[99] Brunetti CR, Paulose-Murphy M, Singh R, Qin J, Barrett JW, Tardivel A, et al. A secreted high-affinity inhibitor of human TNF from Tanapox virus. Proc Natl Acad Sci USA 2003;100:4831-6.
[100] Sumner RP, Maluquer de Motes C, Veyer DL, Smith GL. Vaccinia virus inhibits NF-kappaB-dependent gene expression downstream of p65 translocation. J Virol 2014;88:3092-102.

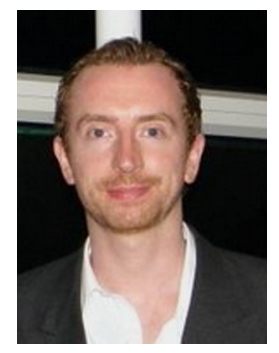

Gareth Brady studied poxviral immune evasion during his Ph.D. in Trinity College Dublin, focusing on novel orthopoxviral immunomodulators. After his Ph.D. was awarded in 2005 he moved to Imperial College London where he worked on the modulation of B cell growth by the gammaherpesvirus Epstein Barr Virus and characterized a novel cross-regulation of host transcription factors by the virus. He was recently awarded a Marie Curie Fellowship to return to Trinity College Dublin and is currently investigating ways in which Molluscum contagiosum virus evades human inflammation and immunity.

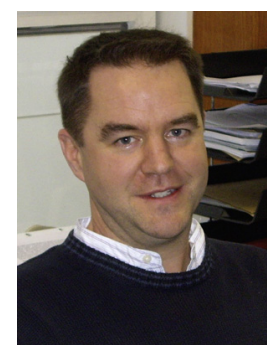

Andrew Bowie currently works in the School of Biochemistry and Immunology, Trinity College Dublin. He obtained his Ph.D. in Biochemistry from TCD in 1997, and was appointed to his current post in 2001. He was elected a Fellow of TCD in 2008, and a member of the Royal Irish Academy in 2014. His research interests include how viruses are initially detected by the innate immune system, leading to the activation of transcription factors such as NF-kappaB and IRF3, and to the induction of cytokines and interferons. A particular current interest is how DNA is sensed by the innate immune system. 